\title{
A Classification Model to Evaluate the Security Level in a City Based on GIS-MCDA
}

\author{
Ciro José Jardim de Figueiredo and Caroline Maria de Miranda Mota \\ Management Engineering Department, Federal University of Pernambuco, P.O. Box 7462, 50630-970 Recife, PE, Brazil \\ Correspondence should be addressed to Ciro José Jardim de Figueiredo; figueiredocj@yahoo.com.br
}

Received 6 January 2016; Revised 13 April 2016; Accepted 26 April 2016

Academic Editor: Juan C. Leyva

Copyright ( 2016 C. J. J. Figueiredo and C. M. M. Mota. This is an open access article distributed under the Creative Commons Attribution License, which permits unrestricted use, distribution, and reproduction in any medium, provided the original work is properly cited.

\begin{abstract}
The aim of this paper is to map the most favorable locations for the occurrence of robberies in the Brazilian city through the multicriteria method Dominance-Based Rough Set Approach. Considering the city divisions with alternatives and evaluating by several spatial criteria, a decision-maker is building a preference model with based previous knowledge. Next, decision rules induced from preference information are introduced to the spatial environment to get the results. The decision rules can be seen as conditional part (represented by criteria) and decision part (assignment to decision classes). The rules classify all the alternatives according to security level. Moreover, the rules help to understand the social dynamics of the city and to assist in the proposition of strategies against violence.
\end{abstract}

\section{Introduction}

The issues of public safety and violence are often discussed because they directly affect each person living in society. In general, understanding and explaining the occurrence of violence require significant efforts to collect information on the issue. Information such as crime rates and socioeconomic variables associated with the population is important for the development of new research $[1,2]$. Then the data can be used to create strategic options that will help to combat violence.

For Andresen [3], field studies of violence require more than discrete data. It is necessary to assess the evolution of violence over time and space for decision-making in public security. According to Elmes and Roedl [4], the Geographic Information System (GIS) is an important tool to support this decision-making process and formulate strategies to combat crime.

In the literature, the use of GIS in the field of criminality has already been reported in several different contexts. Various studies show themes and applications such as the identification of crime spatial patterns [4], spatial diversity of crimes [5], spatial correlation between crime and inequality $[2,6]$, and simulation and agent-based models for exploring crime patterns [7]. However, our intention is to provide an alternative technique, using GIS within the context of crime. This technique explores several factors that can help to understand violence.

Therefore, by evaluating different areas as alternatives and the impact of the multiple criteria with respect to violence, we used Multicriteria Decision-Making (MCDM). The primary objective of MCDM is to assist a decisionmaker (DM) in choosing, ordering, or sorting a given set of two or more alternative criteria [8]. Moreover, several studies demonstrate the importance of the MCDM in many research fields [9-11]. In our case, we also considered the features of the spatial information supported by GIS. In the literature, there are very few studies of the combined use of MCDM and GIS to criminality. Gurgel and Mota [12] presented a GIS-MCDM model to prioritize regions for allocation resources considering several criteria; and in [13] a multicriteria approach was proposed aimed at setting police patrol sectors.

The focus of this study is to build a GIS-MCDM model to assess the level of security (increase in crime) in a city. The present study can be divided into two main contributions. First, we discuss the classification of the spatial alternatives to evaluate the level of security and its relationship to criminality using a GIS-MCDM approach. Second, we discuss how the 
results of the model can be used in the formulation of security policies and which criteria are most important.

The rest of the paper is divided as follows. Section 2 presents background information illustrating the importance of GIS-MCDM. Section 3 presents the MCDM method used in the application. In Section 4, we present a model of the problem and describe the procedures used. In Section 5, we apply and discuss the results that were obtained. In Section 6, we present our conclusions and perspectives for future studies.

\section{Background on GIS-MCDM}

The MCDM approach assists in building an aggregation model based on the preference information sourced by the DM [14]. For Dyer et al. [15], since the 1980s MCDM methods have been implemented in computer systems to support the decision-making process and have subsequently been called Decision Support Systems (DSS). In recent years, authors have explored MCDM methods in different applications [1618].

Specifically, there has been a growth in the use of GIS with MCDM because of the development computerized systems and improved access by users [19]. This combination is important because spatial decision problems typically involve several alternatives assessed by conflicting multiple criteria. Also, the evaluation is conducted by a DM or group of decision-makers [20]. Afterwards the concept of GIS-based Multicriteria Decision-Making (GIS-MCDM) emerged [19].

In the recent literature, several studies have combined the decision process using GIS and MCDM such as choosing a better route for vehicles [21], identifying sustainable sites for environmental conservation [20, 22], sorting regions to implement energy mixes [23], allocating industries [24], and suitable land use [25].

We also observed that authors have evaluated specific combination MCDM methods with GIS. The adaptation of GIS-MCDM needs to create a synergy that might facilitate the aggregation of information. In this sense, [20, 26, 27] have presented studies using the importance of scales to assess alternatives based on DM preferences or situations involving uncertainty.

On the contrary, authors have shown more traditional methods including both compensatory and noncompensatory methods. In the compensatory methods, AHP was integrated into the GIS environment [28, 29]. Noncompensatory methods present practical applications with ELECTRE and other outranking methods $[22,30]$. Also, there are software packages to facilitate the generation of recommendations to decision-makers [30].

Thus, the possibilities are extensive for combining the GIS-MCDM approach to support decision-making processes that directly involve the spatial use. However, there are a few studies that use GIS-MCDM for the public security field [12, 13]. Thus, the gap related with GIS-MCDM and criminality becomes a motivator for building a model to solve specific problems in public safety.

\section{DRSA Method}

In this section, we present Dominance-Based Rough Set Approach (DRSA) method that was integrated with GIS. We choose a method that allows using the set of reference examples (real or fictitious) for aggregating the information from preference obtained with the DM. Thereafter, each reference alternative of the set is allocated in preordered classes $[31,32]$. To arrive in results, the DRSA method consider the preference model in the form of a set of "IF...THEN..." decision rules discovered from the data by inductive learning $[14,32]$.

Highlighted DRSA method, the absence in weights, and preference thresholds used by DM avoiding a high cognitive effort are required. The reference examples are used as input to get DM's preference information. Moreover, there is an interactive construction between the DM and the analyst. The rules are transparent and easy to interpret for the DM and give arguments to justify and explain the decision.

3.1. Notations Used. Let set of alternatives be finite, discrete, and nonempty $n, A=\left\{a_{1}, a_{2}, \ldots, a_{n}\right\}$.

Let a finite, discrete, and nonempty set of alternatives $A^{*}=\left\{a_{1}^{*}, \ldots, a_{k}^{*}, \ldots\right\}$ assuming $A^{*} \subseteq A$, called the set of reference examples where the DM wishes to express his/her preferences for a given problem.

Also, let a collection of finite and nonempty set of criteria $m, C=\left\{c_{1}, c_{2}, \ldots, c_{m}\right\}$, and each alternative has an evaluation criterion $c_{m}\left(a_{k}^{*}\right)$ for all $a_{k}^{*} \in A^{*}$. Thus, for two alternatives $a_{1}^{*}$ and $a_{2}^{*} \in A^{*}$, we have $c_{m}\left(a_{1}^{*}\right) \gtrsim c_{m}\left(a_{2}^{*}\right)$ which means that " $a_{1}^{*}$ is at least as good in relation to $a_{2}^{*}$ when compared with criteria $c_{m}$ ", representing a weak preference relation between both alternatives pairs [32]. We also assume that these criteria are preference ordered with two types: cost criteria (the smaller the better) and gain criteria (the greater the better).

In addition $\mathrm{Cl}=\left\{\mathrm{Cl}_{t}, t \in T\right\}$, with $T=\{1, \ldots, j\}$, such that $a_{1}^{*} \in A^{*}$ must belong to one and only one class $\mathrm{Cl}_{t} \in \mathrm{Cl}$. Each class is called decision class. Assuming too that these classes are ordered for all and any $r$ and $s \in T$, such as $r>s$, the actions included in $\mathrm{Cl}_{r}$ are preferred over the actions contained in $\mathrm{Cl}_{s}$. The sets to be approximated are called upward and downward unions of decision classes, respectively (see (1) and (2)). Consider

$$
\begin{aligned}
& \mathrm{Cl}_{t}^{\geq}=\bigcup_{s \geq t} \mathrm{Cl}_{s}, \\
& \mathrm{Cl}_{t}^{\leq}=\bigcup_{s \leq t} \mathrm{Cl}_{s}, \quad t=1, \ldots, j .
\end{aligned}
$$

It is assumed that for each evaluation of the alternatives with respect to criteria having a strictly monotonicity relationship with decision class, we can define the dominance relation according to [32]. Let $P \subseteq C$ be a subset of condition criteria; we can say that $a_{1}^{*}$ dominates $a_{2}^{*}$ in the condition criteria space (denoted by $a_{1}^{*} D_{p} a_{2}^{*}$ ) if $a_{1}^{*} \gtrsim a_{2}^{*} \forall c \in P$. Assuming, without loss of generality, that the domains of the criteria are numerical and that they are ordered so that the preference increases with the value, we can say that $a_{1}^{*} D_{p} a_{2}^{*}$ 
is equivalent to $a_{1}^{*} \geq a_{2}^{*} \forall c \in P, P \subseteq C$. The analogous definition holds in the decision class space [32].

In DRSA, the granules of knowledge used for approximation are dominance cones that are defined as follows in objects that are dominating and dominated, respectively, with respect to $P$ :

$$
\begin{aligned}
& D_{P}^{+} a_{1}^{*}=\left\{a_{2}^{*} \in A^{*}: a_{2}^{*} D_{P} a_{1}^{*}\right\}, \\
& D_{P}^{-} a_{1}^{*}=\left\{a_{2}^{*} \in A^{*}: a_{1}^{*} D_{P} a_{2}^{*}\right\} .
\end{aligned}
$$

Finally, the upper and lower approximations of unions of decision classes with respect to $P$ are calculated as follows:

(i) The $P$-upper approximation of $\mathrm{Cl}_{t}^{\geq}: \bar{P}\left(\mathrm{Cl}_{t}^{\geq}\right)=\left\{a_{1}^{*} \epsilon\right.$ $\left.A^{*}: D_{P}^{-}\left(a_{1}^{*}\right) \cap \mathrm{Cl}_{t}^{\geq} \neq \emptyset\right\}$.

(ii) The $P$-lower approximation of $\mathrm{Cl}_{t}^{\geq}: \underline{P}\left(\mathrm{Cl}_{t}^{\geq}\right)=\left\{a_{1}^{*} \epsilon\right.$ $\left.A^{*}: D_{P}^{+}\left(a_{1}^{*}\right) \subseteq \mathrm{Cl}_{t}^{\geq}\right\}$.

(iii) The $P$-upper approximation of $\mathrm{Cl}_{t}^{\leq}: \bar{P}\left(\mathrm{Cl}_{t}^{\leq}\right)=\left\{a_{1}^{*} \epsilon\right.$ $\left.A^{*}: D_{P}^{+}\left(a_{1}^{*}\right) \cap \mathrm{Cl}_{t}^{\leq} \neq \emptyset\right\}$.

(iv) The $P$-lower approximation of $\mathrm{Cl}_{t}^{\leq}: \underline{P}\left(\mathrm{Cl}_{t}^{\leq}\right)=\left\{a_{1}^{*} \epsilon\right.$ $\left.A^{*}: D_{P}^{-}\left(a_{1}^{*}\right) \subseteq \mathrm{Cl}_{t}^{\leq}\right\}$.

Finally, the $P$-boundaries (doubtful regions) of the unions $\mathrm{Cl}_{t}^{\geq}$and $\mathrm{Cl}_{t}^{\leq}$are defined, respectively, as follows:

$$
\begin{aligned}
& B n_{P}\left(\mathrm{Cl}_{t}^{\geq}\right)=\bar{P}\left(\mathrm{Cl}_{t}^{\geq}\right)-\underline{P}\left(\mathrm{Cl}_{t}^{\geq}\right), \\
& B n_{P}\left(\mathrm{Cl}_{t}^{\leq}\right)=\bar{P}\left(\mathrm{Cl}_{t}^{\leq}\right)-\underline{P}\left(\mathrm{Cl}_{t}^{\leq}\right) .
\end{aligned}
$$

To evaluate the results using the sample of the reference examples, the DRSA apply the accuracy of approximation. For any $t \in T$ and for any $P \subseteq C$ the accuracy is defined as $\mathrm{Cl}_{t}^{\geq}$and $\mathrm{Cl}_{t}^{\leq}$by $P$ as the respective ratios (see (7) and (8)). Consider

$$
\begin{aligned}
& \alpha_{P}\left(\mathrm{Cl}_{t}^{\geq}\right)=\frac{\operatorname{card}\left(\underline{P}\left(\mathrm{Cl}_{t}^{\geq}\right)\right)}{\operatorname{card}\left(\bar{P}\left(\mathrm{Cl}_{t}^{\geq}\right)\right)}, \\
& \alpha_{P}\left(\mathrm{Cl}_{t}^{\leq}\right)=\frac{\operatorname{card}\left(\underline{P}\left(\mathrm{Cl}_{t}^{\leq}\right)\right)}{\operatorname{card}\left(\bar{P}\left(\mathrm{Cl}_{t}^{\leq}\right)\right)} .
\end{aligned}
$$

From the accuracy approximation we can obtaining the quality approximation (see (9)). It expresses the ration of all $P$-correctly sorted reference examples to all reference examples in the table. For every minimal $P \subseteq C$ we define such that $\gamma_{P}(\mathrm{Cl})=\gamma_{C}(\mathrm{Cl})$ is called a reduct of $\mathrm{Cl}$ and denoted by $\operatorname{RED}_{\mathrm{Cl}}(P)$. The intersection of all of the reducts is called the core and denoted by $\mathrm{CORE}_{\mathrm{Cl}}$ :

$$
\begin{aligned}
\gamma_{P}(\mathrm{Cl}) & =\frac{\operatorname{card}\left(A^{*}-\left(\bigcup_{t \in T} B n_{P}\left(\mathrm{Cl}_{t}^{\leq}\right)\right)\right)}{\operatorname{card}\left(A^{*}\right)} \\
& =\frac{\operatorname{card}\left(A^{*}-\left(\bigcup_{t \in T} B n_{P}\left(\mathrm{Cl}_{t}^{\geq}\right)\right)\right)}{\operatorname{card}\left(A^{*}\right)} .
\end{aligned}
$$

The decision rules are the final of the DRSA method and are divided in two parts: condition and decision, where the condition part specifies the values assumed by one or more criteria and the decision part specifies an assignment to one decision class [33].

\section{Development of GIS-MCDM Model for Public Safety}

The present study shows the usefulness of the GIS-MCDM approach, using DRSA method. In this the section we expose the steps of the GIS-MCDM model for public safety and application performed on a real problem.

4.1. Steps of the GIS-MCDM. The integration between the DRSA method with spatial data is made in two systems. All evaluations for choosing the reference examples are prepared in a GIS environment, which avoids the decision table to realize the same procedure. Moreover, the visualization of data becomes better understood by the DM. However, to execute DRSA, we used the free software called jMAF (available at http://idss.cs.put.poznan.pl/).

The construction of the model comprises two integrated processes. The first is the selection of the reference examples using the maps, which contains the numeric values for each criterion (layers). Each layer is a set of alternatives evaluated by one criterion. The DM chooses the same subset of alternatives considering all criteria. Next, each alternative is allocated to only one predefined class. These procedures are performed in ArcGis 10.1 and exported to the second step.

In second procedure, the alternatives are evaluated for each criterion and each alternative is allocated in only one decision class [34]. Furthermore, we may get the results in relation to $\bar{P}\left(\mathrm{Cl}_{t}^{\geq}\right)$and $\underline{P}\left(\mathrm{Cl}_{t}^{\geq}\right)$, as well as $\bar{P}\left(\mathrm{Cl}_{t}^{\leq}\right)$and $\underline{P}\left(\mathrm{Cl}_{t}^{\leq}\right)$ for decision classes, and we may obtain the decision rules that are used to map the alternatives. Thereafter, the rules that are exported come back to ArcGis 10.1 and are implemented on the Python environment to classify all the alternatives. The decision rules are divided in the condition criteria part (IF) and decision classes part (THEN). This permits the interactive decision process to be with the DM. Because if the DM does not agree with the results, he/she can change the $A^{*} \subseteq A$ set. Figure 1 shows the flowchart with the procedures.

\section{An Application with Real Data}

In this section, we present the results of the application using real data. As follows, the model is performed with other subsets of the reference examples. Finally, we bring a discussion about the impact on the security policies.

5.1. Results of the Model GIS-MCDM. We performed an application using real data in the city of Recife, the state capital of Pernambuco, the second most populous city in Northeastern Brazil. According to Ratton et al. [35], Recife was very violent, but the violence decreased because of to the Pact for Life program, which was established in 2007 by the Government of Pernambuco. The Pact for Life program aimed to suppress the violence that plagued the state by using laws to punish crime and strategies to the violence. However, 


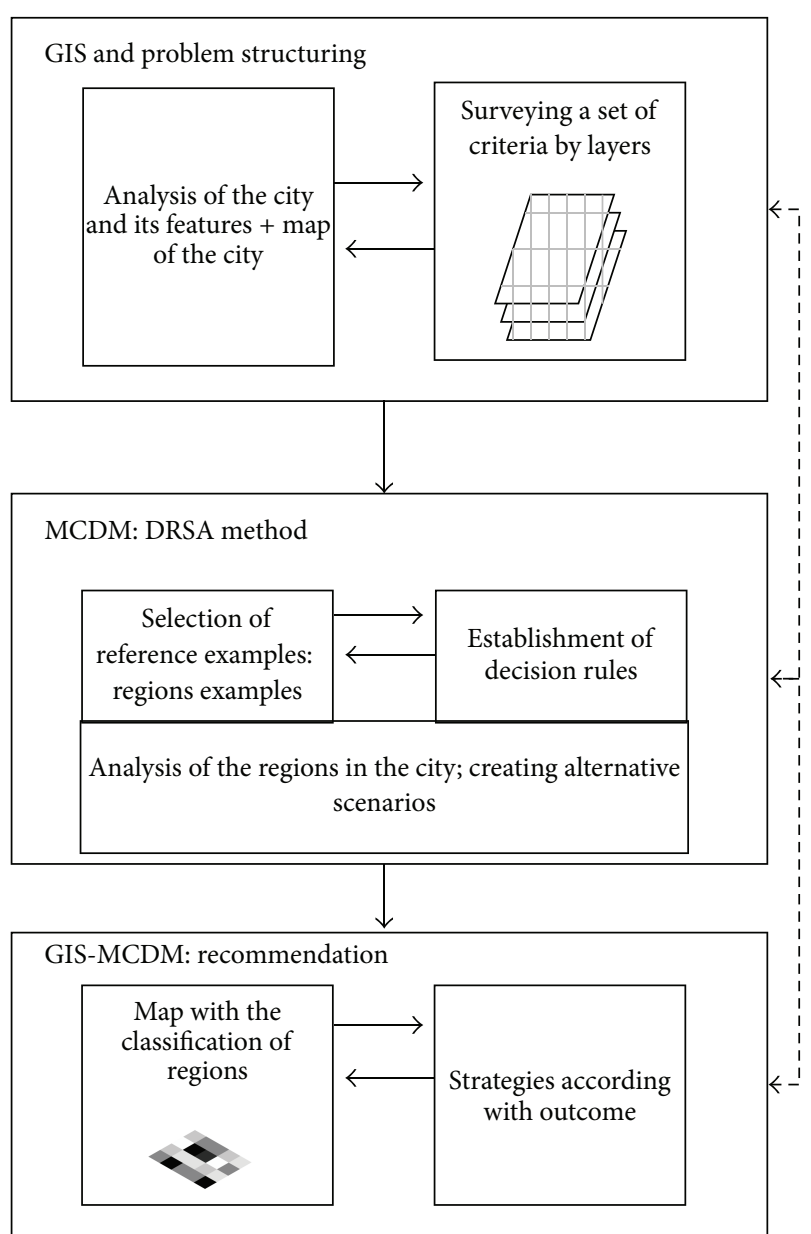

FIGURE 1: Flowchart used in the construction of the GIS-MCDM model.

there are still many challenges to be overcome in the program to improve it before it can fully benefit society [35].

Recife city has a spatial division called the Human Development Units (HDUs). Each unit is an alternative and is evaluated according to the criteria used in this problem. The territory that was used to perform this application is composed of 62 alternatives. Figure 2 shows the localization of Recife city.

To apply the proposed approach, different criteria were built with the base in factors that have been indicated by authors of specialized literature that explain how there are the increases in violence. In our case, these criteria explain how the increase or decrease in the occurrence influence robbery. About the issue, Andresen [3] and Levitt [36] provided detailed discussion of how related factors such as unemployment and low income affect the occurrence of crimes. For instance, a person who had no chance of working becomes motivated to commit crime in terms of disadvantaged conditions in which he or she lives. On the other hand, Fajnzylber et al. [37] and Frank et al. [5] state that there are many different factors that influence the occurrence of robbery, such as socioeconomic factors, physical environment, and demographic density, and that these factors end up being disaggregated into various peices of information related to these features.

We also check that the issue of crime is treated directly within spatial context $[4,6]$; therefore, there is a motivation to use the factors that can be used to map areas that are more or less secure. In this sense, there are studies that aggregate information about the occurrence of crime to evaluate the safety level as expressed above. However, there is no preference aggregation of the DM or other criteria built by DM, with $[12,13]$ being an exception. Consequently, this study serves to identify areas where there are more crimes. Then, we select the approach GIS-MCDM to create resultsbased preference model.

Based on these factors exposed, we raised criteria that can be taken into account to evaluate the city in relation to the safety level. In our case, the criteria have a relation with robbery and are presenting a preference ordered. For the city of Recife, we consider a total of five criteria that influence the occurrence of this type of crime; these are described in Table 1, and the 2005 Atlas of Human Development in Recife was used as the data source.

When applying MCDM methods there is a difficulty in determining the contribution of each criterion in the problem (or even the relative importance). Therefore, in the DRSA method, this step of inserting information concerning the criteria is not used, and every criterion has equal importance. However, as this is a classification problem, it is necessary to assign each class a level of preference, and, in our case, this reflects the level of safety with which it is associated.

Given the criteria, five classes $(\mathrm{Cl})$ were determined according to the preferences of the DM: $\mathrm{Cl}_{\text {Very high }}>\mathrm{Cl}_{\text {High }}>$ $\mathrm{Cl}_{\text {Moderate }}>\mathrm{Cl}_{\text {Low }}>\mathrm{Cl}_{\text {Very low }}$. Thus $\mathrm{Cl}_{\text {Very high }}$ is a place with a low incidence of robberies and a very high level of security while $\mathrm{Cl}_{\text {Very low }}$ is a place with a high incidence of robberies and a very low level of security.

The exploration of the map in the initial model phase enables the choice of reference examples in the map of Recife city. Each alternative has information about the criteria and is displayed on the map to DM. In Figure 3 we present alternatives evaluated by each criterion. The values were grouped by ArcGis (this function can be called Natural breaks). Next, the data is exported in table format (.txt). We established the initial classification decision table, where the rows contain the alternatives chosen by the DM and columns contain the criteria. A decision class evaluated by the DM is listed in the final column. In Table 2, we list reference examples that were used.

Firstly, DRSA method was applied using the data from Table 2. After the quality of the results was evaluated. According to the definition in Section 3.1, an accuracy of approximation was equal to 1 in both $\mathrm{Cl}_{t}^{\geq}$and $\mathrm{Cl}_{t}^{\leq}$for all the decision classes. The quality of approximation was also equal to 1 . Consequently, the reference examples are suitable to obtain precise classification and have a strong ability that will be used in the classification of the other alternatives.

The outcomes reveal two reducts: $\mathrm{RED}_{\mathrm{Cl}}$ (Gini, Infrastructure, Demographic density, and Education); $\mathrm{RED}_{\mathrm{Cl}}$ (Gini, Income, Infrastructure, and Demographic density). Therefore, the $\mathrm{CORE}_{\mathrm{Cl}}$ is represented by the following criteria: Gini 


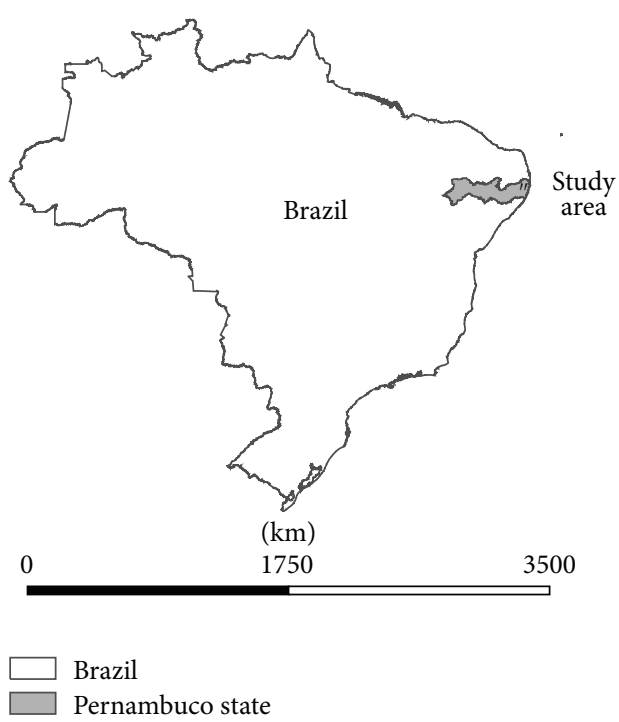

(a)

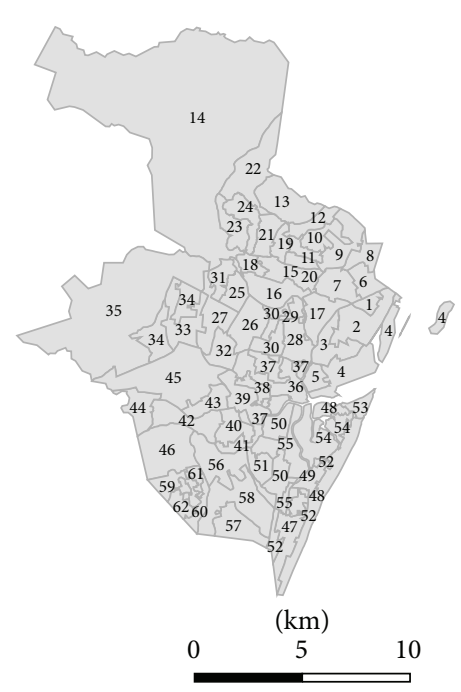

Recife city

Figure 2: (a) Brazil and Pernambuco state and (b) Recife city with alternatives.

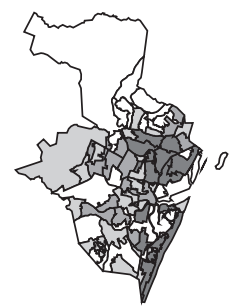

Income

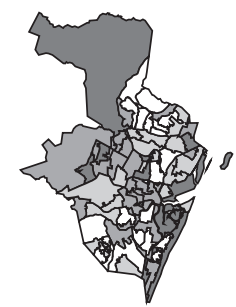

Gini index

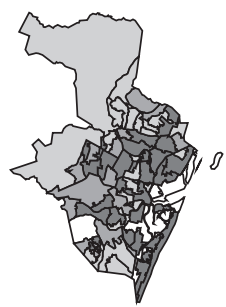

Infrastructure

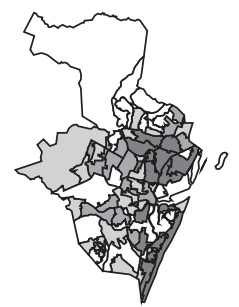

Education

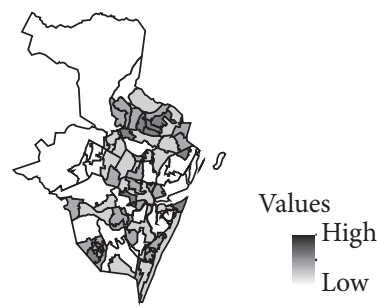

Demographic density

FIGURE 3: Alternatives considering each criterion.

TABLE 1: Criteria used with descriptive values.

\begin{tabular}{|c|c|c|c|c|c|c|}
\hline Criterion & $\begin{array}{l}\text { Maximum } \\
\text { value }\end{array}$ & $\begin{array}{l}\text { Minimum } \\
\text { value }\end{array}$ & Mean & $\begin{array}{l}\text { Standard } \\
\text { deviation }\end{array}$ & Preference & Definition \\
\hline $\begin{array}{l}\text { Income, } \mathrm{R}^{*} \text { (by } \\
\text { person) }\end{array}$ & 1863.64 & 86.15 & 378.66 & 400 & Gain & $\begin{array}{l}\text { The lower the income of the } \\
\text { person the greater the chances of } \\
\text { the person committing a crime }\end{array}$ \\
\hline Gini index & 0.72 & 0.40 & 0.52 & 0.05 & Cost & $\begin{array}{l}\text { Measuring the distribution of the } \\
\text { income; if less, then people have } \\
\text { equal distribution }\end{array}$ \\
\hline $\begin{array}{l}\text { Infrastructure } \\
\text { (bathroom and piped } \\
\text { water\%) }\end{array}$ & 99.59 & 48.53 & 83.57 & 12.40 & Gain & $\begin{array}{l}\text { The precarious condition makes } \\
\text { the place prone to crime }\end{array}$ \\
\hline Education (years) & 13 & 4 & 7.36 & 2.36 & Gain & $\begin{array}{l}\text { The better education conditions } \\
\text { decrease the chances of people } \\
\text { getting involved in crime }\end{array}$ \\
\hline $\begin{array}{l}\text { Demographic density } \\
\text { per } \mathrm{km}^{2}\end{array}$ & 28422 & 355 & 12390 & 6617 & Cost & $\begin{array}{l}\text { The population increase makes } \\
\text { the environment more propitious } \\
\text { for making off after the crime }\end{array}$ \\
\hline
\end{tabular}

\footnotetext{
${ }^{*}$ For each US $\$ 1.00$ equal R $\$ 3.80$.
} 
TABLE 2: Reference examples evaluated by criteria and decision class.

\begin{tabular}{|c|c|c|c|c|c|c|}
\hline HDU code & Gini & Income & Infrastructure & Demographic density per $\mathrm{km}^{2}$ & Education & Decision class \\
\hline 16 & 0.50 & 1353.42 & 94.74 & 6436 & 11.73 & 1 \\
\hline 19 & 0.47 & 126.0 & 75.00 & 23956 & 5.51 & 1 \\
\hline 21 & 0.45 & 141.47 & 78.81 & 18506 & 5.97 & 1 \\
\hline 15 & 0.52 & 902.38 & 97.31 & 10888 & 10.58 & 2 \\
\hline 20 & 0.47 & 158.00 & 78.00 & 28220 & 6.12 & 2 \\
\hline 7 & 0.50 & 893.13 & 94.45 & 8796 & 11.09 & 3 \\
\hline 35 & 0.55 & 187.10 & 78.24 & 1516 & 6.55 & 3 \\
\hline 45 & 0.50 & 143.00 & 89.00 & 1930 & 5.52 & 3 \\
\hline 2 & 0.50 & 616.00 & 98.00 & 3927 & 10.27 & 4 \\
\hline 3 & 0.50 & 868.60 & 99.00 & 6577 & 11.20 & 4 \\
\hline 48 & 0.61 & $1,864.00$ & 96.00 & 9887 & 11.77 & 4 \\
\hline 4 & 0.60 & 169.00 & 67.00 & 1893 & 5.64 & 5 \\
\hline 50 & 0.47 & 571.00 & 95.00 & 6739 & 10.09 & 5 \\
\hline
\end{tabular}

TABLE 3: Decision rules generated by the DOMLEM.

\begin{tabular}{|c|c|c|c|}
\hline Rule ID & Rule description & Class & Number of supporting objects \\
\hline Rule 1 & IF $($ gini $\leq 0.47)$ THEN & At least very high & 2 \\
\hline Rule 2 & IF (inc $\geq 1353.42$ ) THEN & At least very high & 1 \\
\hline Rule 3 & IF $($ gini $\leq 0.47)$ THEN & At least high & 3 \\
\hline Rule 4 & IF (inc $\geq 902.38$ ) THEN & At least high & 2 \\
\hline Rule 5 & IF (inc $\geq 893.13$ ) THEN & At least moderate & 3 \\
\hline Rule 6 & IF $($ demog $\leq 1516)$ THEN & At least moderate & 1 \\
\hline Rule 7 & IF $($ gini $\leq 0.50) \&($ demog $\leq 1930)$ THEN & At least moderate & 1 \\
\hline Rule 8 & IF $(\mathrm{edu} \geq 10.27)$ THEN & At least low & 6 \\
\hline Rule 9 & IF $($ infr $\geq 89) \&($ demog $\leq 1930)$ THEN & At least low & 1 \\
\hline Rule 10 & IF (infr $\leq 67.00)$ THEN & At most very low & 1 \\
\hline Rule 11 & IF $($ gini $\geq 0.47) \&($ demog $\geq 6739) \&(e d u \leq 10.09)$ THEN & At most very low & 1 \\
\hline Rule 12 & IF (gini $\geq 0.60)$ THEN & At most low & 2 \\
\hline Rule 13 & IF $($ gini $\geq 0.50) \&($ inc $\leq 868.6) \&($ demog $\geq 3927)$ THEN & At most low & 3 \\
\hline Rule 14 & IF $($ gini $\geq 0.47) \&($ inc $\leq 571.00) \&($ demog $\geq 6739)$ THEN & At most low & 2 \\
\hline Rule 15 & IF $($ gini $\geq 0.47) \&($ inc $\leq 893.13)$ THEN & At most moderate & 8 \\
\hline Rule 16 & IF $($ gini $\geq 0.50)$ THEN & At most high & 6 \\
\hline Rule 17 & IF $($ demog $\geq 28220)$ THEN & At most high & 1 \\
\hline
\end{tabular}

Index, Infrastructure, and Demographic density. These are the three criteria that are adequate to explain the decision, according to the DRSA method.

Then, we performed the jMAF system to create the decision rules by the DOMLEM algorithm. Using the algorithm we can obtain 17 deterministic certain decision rules from 13 reference examples in total. Those decision rules represent the certain knowledge. The certain rules are originated from $P$-lower approximation of $\underline{P}\left(\mathrm{Cl}_{t}^{\geq}\right)$and $\underline{P}\left(\mathrm{Cl}_{t}^{\leq}\right)$of the union class. The decision rules can be implanted directly into a GIS environment to generate the results to all the alternatives and those presented in Table 3.

Given the decision rules, we can compare the remaining alternatives that do not belong in Table 2. The results are presented in the form of map, where the darker alternatives need more attention, because they have a lower level of security. In Figure 4 the following are the classification in the all alternatives for the Recife city.

Therefore, we can draw some conclusions about the results:

(i) HDU 52 is classified as at most very low. Therefore, it is a place with high chances for robbery occurrence. When we compare criteria evaluations with Rules 10 and 11, we can see that the alternative complies with both rules. Also, HDU 52 has a Gini Index equal to 0.72 , demonstrating a high social inequality among its inhabitants.

(ii) The alternatives 10 and 11 are encircled by other alternatives that were classified as being more prone 


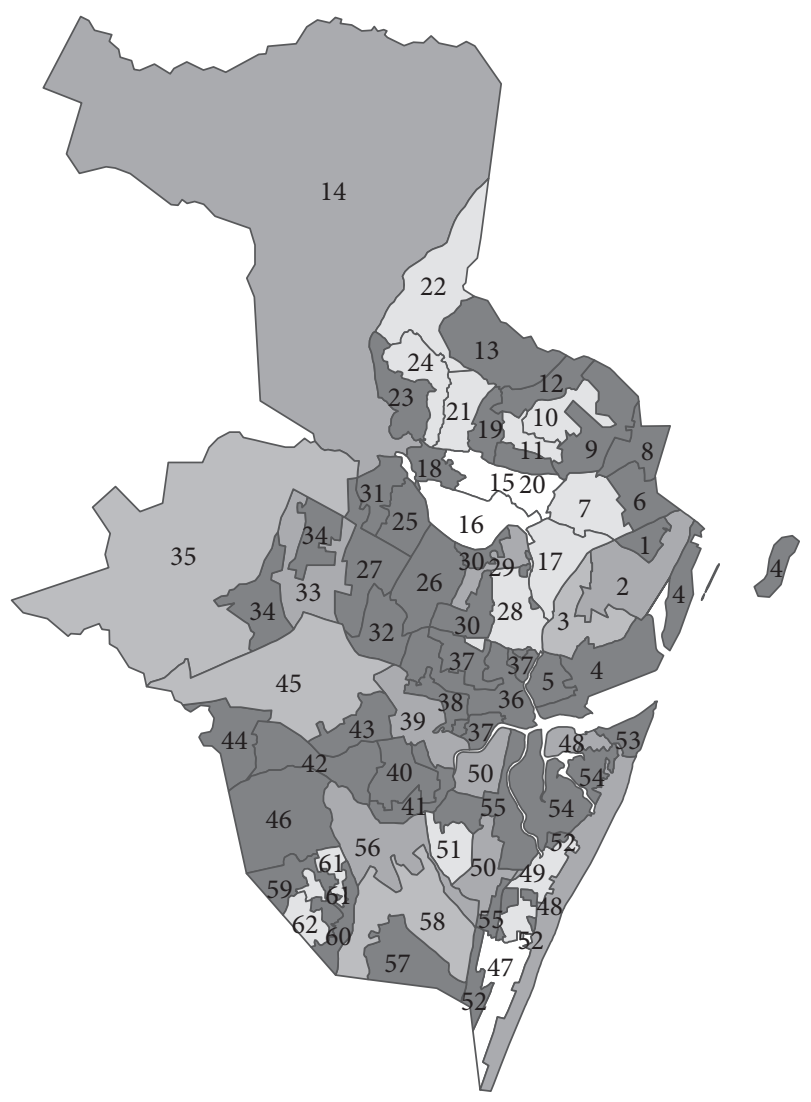

Security level
Very high
High

Moderate

FIGURE 4: The classification using GIS-MCDM model for security public.

to robbery, because the criminal proliferation varies over space and time. Some alternatives fit certain rules while other alternatives are explained by other kinds of rules.

(iii) The spatial proximity of the alternatives is also highlighted. The HDUs that present darker color are neighboring other alternatives with the same color, because of the proximity along the criteria values.

5.2. Discussion. Let us now consider the change in the reference examples as an option for DM and discuss the results in the case involving a security problem. Each alternative is described in terms of the decision rules and rules have both representation and recommendation tasks. Then, we modified the data presented in Table 2 resulting in new decision rules, but these alterations maintain the readiness to interpret the results according to the DRSA method [14]. We also kept the same number of the reference examples. Either some examples that belong in Table 2 were changed by new examples or they just altered the class. Consequently, we want to check the impact presented by the new results.
The most important argument for the proposal of several rules is the fact that these rules may be applied in different results. However, it is important to discover if the alternatives swapped their security level. For instance, HDU 33 was allocated in $\mathrm{Cl}_{\text {Low }}$, as can be seen in Figure 4, which takes into account Rules 8, 12, and 13. After the new application of the model, this alternative was assigned to $\mathrm{Cl}_{\text {Very low }}$ class. Now, the rules that are classified in $\mathrm{Cl}_{\text {Low }}$ modified their values and HDU 33 complies with condition rules that classify $\mathrm{Cl}_{\text {Very low }}$. On the contrary, for HDUs 17 and 28, both changed from $\mathrm{Cl}_{\text {High }}$ to $\mathrm{Cl}_{\text {Very high }}$ class. Now, these alternatives can be considered of high level of security. The results are presented in Figure 5, which shows that some alternatives changed to new classes.

Moreover, the other remarks consider the decision rules and the remaining results. In the second result, there was only reduct and only $\mathrm{CORE}_{\mathrm{Cl}}$ (Gini, Infrastructure, and Demographic density). The number of rules decreased to 15 , while the quality and accuracy were kept with the same values. Therefore, the examples were also suitable to explain all the data of the problem. That decision rule highlighted other combinations. For instance, IF (gini $\geq 0.47$ ) \& (inc $\leq$ 893.13) THEN At most Moderate passed to IF (income $\geq$ 893.13) \& (demog $\leq 1516)$ THEN At most Moderate.

The second part of the section is about the problem of public security and GIS-MCDM. Reference examples in which the DM is given options by MCDM models have been widely reported [31, 38-40]. A multicriteria approach with predefined information enables the DM to know which examples give him/her the opportunity to be more secure. In our case, using the map is most favorable because the DM does not look for alternatives in a table which may represent your preference information. We also avoid other MCDM methods that use weights and preference thresholds to aggregate the preference.

The results of this study can be used to propose strategies to help the police and to enhance public security. The DM may be interested either in increasing police effectiveness or in planning public polices for improvements in certain regions (i.e., a specific set of the HDU). In the second situation, the DM may have a focus on building new schools and developing infrastructure. However, such situation would involve more than one DM, implying the problem of aggregation of group preferences; this situation is not investigated in this paper.

The criteria that are socioeconomic indicators show the discrimination of the values with respect to the security level. Alternatives allocated into $\mathrm{Cl}_{\text {Low }}$ have a mean year of education of 6.47 and 6.97 for first and second results for the Education criteria, respectively. However, HDUs classified in $\mathrm{Cl}_{\text {High }}$ and $\mathrm{Cl}_{\text {Very high }}$ have a mean year of education of 8.63. These mean years present the following results: places more prone to robbery have citizens with little education. The same situation occurs for the criteria: Gini index, Income, and Infrastructure. HDUs with security decreased also present adverse values with relation to all the alternatives (Table 1). The most interesting is the Gini index (means of 0.54 for the alternatives allocated in $\mathrm{Cl}_{\text {Very low }}$ ) because it serves as inequality indicator. 

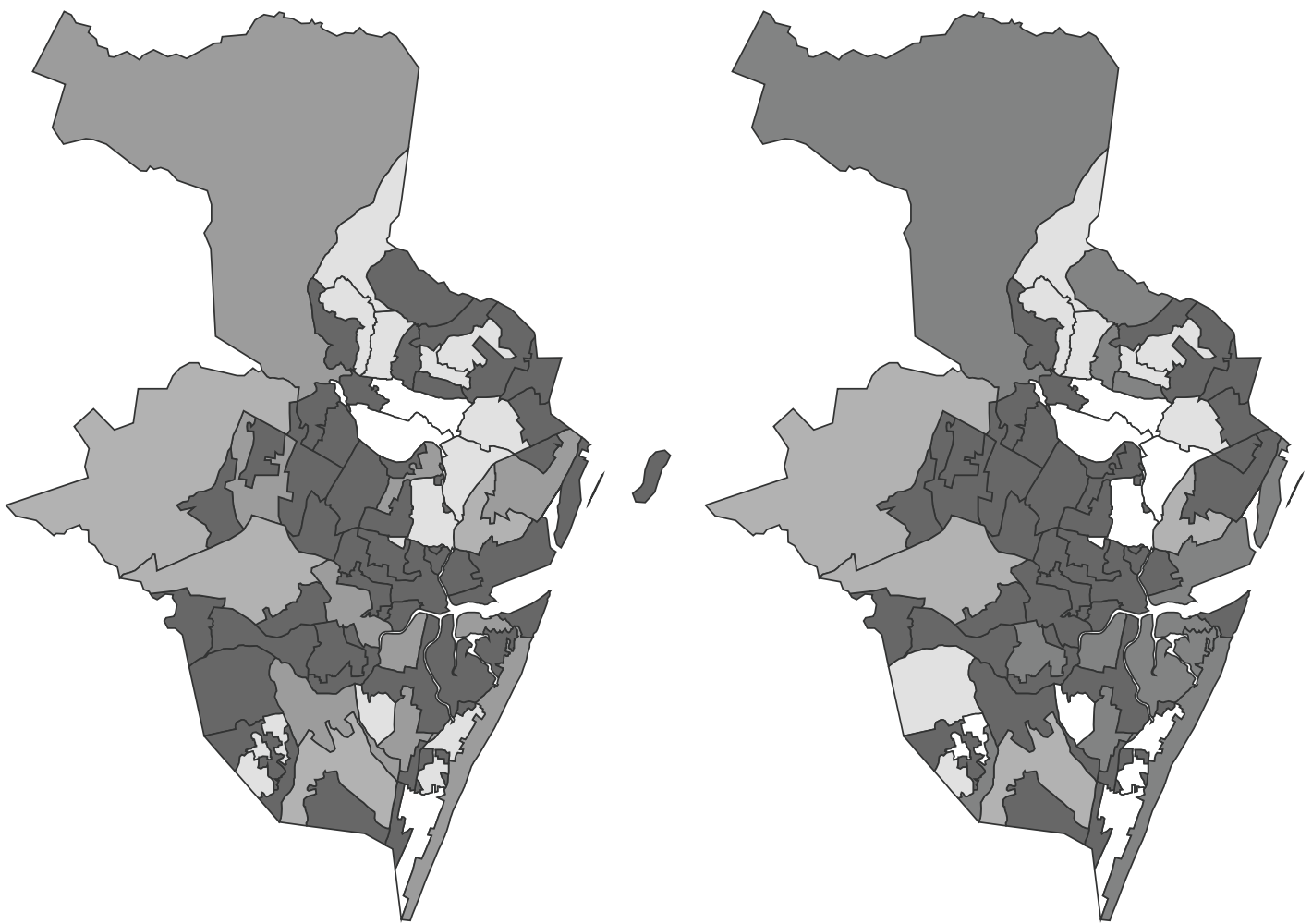

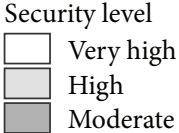

Moderate

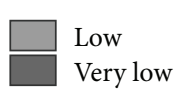

(a)
Security level

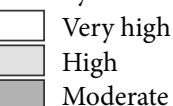

Moderate
Low

Very low

(b)

FIGURE 5: Comparing two results: (a) first results and (b) results using other reference examples.

Another interesting point is to observe how a modification in the reference examples may affect the result. In other words, the DM might want to check how the preference information affects the results through a more general outcome. With respect to the DRSA method, a HDU passing from one class to another is because of the new decision rules. However, we may also see the sensibility of the alternatives and use the results within security strategies. For instance, an alternative that passed to a better class no longer receives attention from the Government. Instead, there was just a change into another class, which yet requires resources to establish a secure place. Therefore, the comparison between changes of the classes is an important consideration. Figure 6 shows each situation.

Still, the second results of the model allow making two conclusions: the intention of the DM to change the set of the reference examples to apply the DRSA method or the participating of more DMs. In the first case, the $\mathrm{DM}$ is interested in using the other examples motivated by preference information. This fact will be necessary in case he/she does not agree with the decision rule. The second case will be the participating new DM. However, there is a problem in how to aggregate the preference for a specific situation in public security.

\section{Conclusion}

In this paper, we discuss the use of a GIS-MCDM approach in order to get a simple and intuitive explanation of the results. We integrate the DRSA method with the GIS tool to evaluate the safety level in Recife, Brazil. The connection in GIS-MCDM was motivated because the spatial information is available, which encourages processes that select soft reference examples. Also, the construction of the model was performed in two steps: (1) selection and evaluation of the reference examples analyzed on the spatial shape using DRSA method and (2) applying the decision rules in GIS tool to generate the final recommendation.

The two contributions expected as the study's objectives were achieved. Firstly, the feasibility of adapting the GISMCDM system and creating a classification problem in a georeferenced environment for the final decision was determined. These results are useful for decision-making and planning to solve public security problems through a proper implementation of the results obtained, which can give a final recommendation for the current decision problem. Then, we checked the impacts caused by the reference examples chosen and they are useful in security policies. Also, alternatives 


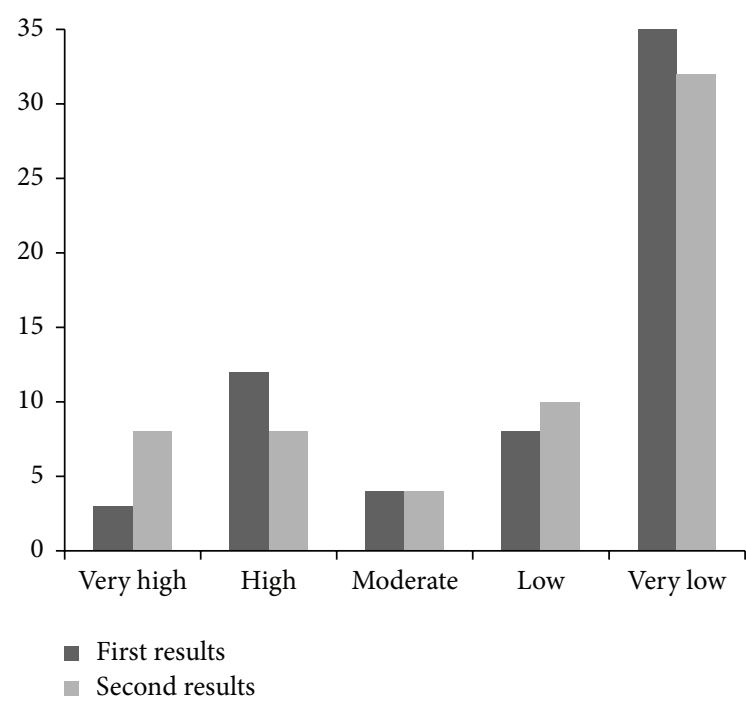

FIGURE 6: Distribution of HDUs class for the two results.

classified as having low level of security have the worst condition based on relation of the criteria.

Finally, the work in view of the junction between GIS and MCDM does not exhaust the possibilities of study in the field of public safety. Other studies would result in group decision-making using methodologies presented in [33, 41, 42] or adopt other multicriteria approach that use combined methods to facilitate the preference aggregation [14].

\section{Competing Interests}

The authors declare that there are no competing interests regarding the publication of this paper.

\section{Acknowledgments}

The authors thank Coordenação de Aperfeiçoamento de Pessoal de Nível de Superior (CAPES) and Brazilian Research Council (CNPq) for the scholarship offered to the student.

\section{References}

[1] B. Kim, T. C. Pratt, and D. Wallace, "Adverse neighborhood conditions and sanction risk perceptions: using SEM to examine direct and indirect effects," Journal of Quantitative Criminology, vol. 30, no. 3, pp. 505-526, 2014.

[2] T. Menezes, R. Silveira-Neto, C. Monteiro, and J. L. Ratton, "Spatial correlation between homicide rates and inequality: evidence from urban neighborhoods," Economics Letters, vol. 120, no. 1, pp. 97-99, 2013.

[3] M. A. Andresen, "Unemployment, business cycles, crime, and the Canadian provinces," Journal of Criminal Justice, vol. 41, no. 4, pp. 220-227, 2013.

[4] G. Elmes and G. Roedl, "The use of geospatial information technology to advance safer college campuses and communities," in Crime Modeling and Mapping Using Geospatial Technologies, pp. 389-413, Springer Science, New York, NY, USA, 2013.
[5] R. Frank, M. A. Andresen, and M. Felson, "The geodiversity of crime: evidence from British Columbia," Applied Geography, vol. 34, pp. 180-188, 2012.

[6] L. G. Scorzafave and M. K. Soares, "Income inequality and pecuniary crimes," Economics Letters, vol. 104, no. 1, pp. 40-42, 2009.

[7] N. Malleson and M. Birkin, "Analysis of crime patterns through the integration of an agent-based model and a population microsimulation," Computers, Environment and Urban Systems, vol. 36, no. 6, pp. 551-561, 2012.

[8] B. Roy, Multicriteria Methodology for Decision Aiding, Kluwer Academic, Dordrecht, Netherlands, 1996.

[9] E. C. B. Oliveira, L. H. Alencar, and A. P. C. S. Costa, "A decision model for energy companies that sorts projects, classifies the project manager and recommends the final match between project and project manager," Production, vol. 26, no. 1, pp. 91104, 2016.

[10] A. T. de Almeida, R. J. P. Ferreira, and C. A. V. Cavalcante, "A review of the use of multicriteria and multi-objective models in maintenance and reliability," IMA Journal of Management Mathematics, vol. 26, no. 3, pp. 249-271, 2015.

[11] L. G. de Oliveira Silva and A. T. de Almeida-Filho, "A multicriteria approach for analysis of conflicts in evidence theory," Information Sciences, vol. 346-347, pp. 275-285, 2016.

[12] A. M. Gurgel and C. M. D. M. Mota, "A multicriteria prioritization model to support public safety planning," Pesquisa Operacional, vol. 33, no. 2, pp. 251-267, 2013.

[13] M. Camacho-Collados, F. Liberatore, and J. M. Angulo, "A multi-criteria Police Districting Problem for the efficient and effective design of patrol sector," European Journal of Operational Research, vol. 246, no. 2, pp. 674-684, 2015.

[14] S. Greco, R. Słowiński, and P. Zielniewicz, "Putting Dominancebased Rough Set Approach and robust ordinal regression together," Decision Support Systems, vol. 54, no. 2, pp. 891-903, 2013.

[15] J. S. Dyer, P. C. Fishburn, R. E. Steuer, J. Wallenius, and S. Zionts, "Multiple criteria decision making, multiattribute utility theory: the next ten years," Management Science, vol. 38, no. 5, pp. 645654, 1992.

[16] E. R. Vaidogas and J. Šakenaite, "Solving the problem of multiple-criteria building design decisions with respect to the fire safety of occupants: an approach based on probabilistic modelling," Mathematical Problems in Engineering, vol. 2015, Article ID 792658, 8 pages, 2015.

[17] M. Shaverdi, M. Akbari, and S. F. Tafti, "Combining fuzzy MCDM with BSC approach in performance evaluation of Iranian private banking sector," Advances in Fuzzy Systems, vol. 2011, Article ID 148712, 12 pages, 2011.

[18] J. Antucheviciene, Z. Kala, M. Marzouk, and E. R. Vaidogas, "Solving civil engineering problems by means of fuzzy and stochastic MCDM methods: current state and future research," Mathematical Problems in Engineering, vol. 2015, Article ID 362579, 16 pages, 2015.

[19] J. Malczewski, "GIS-based multicriteria decision analysis: a survey of the literature," International Journal of Geographical Information Science, vol. 20, no. 7, pp. 703-726, 2006.

[20] A. Ligmann-Zielinska and P. Jankowski, "Spatially-explicit integrated uncertainty and sensitivity analysis of criteria weights in multicriteria land suitability evaluation," Environmental Modelling \& Software, vol. 57, pp. 235-247, 2014. 
[21] B. Feizizadeh and T. Blaschke, "An uncertainty and sensitivity analysis approach for GIS-based multicriteria landslide susceptibility mapping," International Journal of Geographical Information Science, vol. 28, no. 3, pp. 610-638, 2014.

[22] F. Joerin, M. Thérialult, and A. Musy, "Using GIS and outranking multicriteia analysis for land-use suitability assesment," International Journal of Geographical Information Science, vol. 15, no. 2, pp. 153-174, 2001.

[23] J. M. Sánchez-Lozano, J. Teruel-Solano, P. L. Soto-Elvira, and M. Socorro García-Cascales, "Geographical Information Systems (GIS) and Multi-Criteria Decision Making (MCDM) methods for the evaluation of solar farms locations: case study in southeastern Spain," Renewable and Sustainable Energy Reviews, vol. 24, pp. 544-556, 2013.

[24] A. Rikalovic, I. Cosic, and D. Laarevic, "GIS based multi-criteria analysis for industrial site selection," Procedia Engineering, vol. 69, pp. 1054-1063, 2014.

[25] O. Marinoni and A. Hoppe, "Using the analytical hierarchy process to support sustainable use of geo-resources in metropolitan areas," Journal of Systems Science and Systems Engineering, vol. 15, no. 2, pp. 154-164, 2006.

[26] S. P. Gbanie, P. B. Tengbe, J. S. Momoh, J. Medo, and V. T. S. Kabba, "Modelling landfill location using Geographic Information Systems (GIS) and Multi-Criteria Decision Analysis (MCDA): case study Bo, Southern Sierra Leone," Applied Geography, vol. 36, pp. 3-12, 2013.

[27] H. Chen, M. D. Wood, C. Linstead, and E. Maltby, "Uncertainty analysis in a GIS-based multi-criteria analysis tool for river catchment management," Environmental Modelling and Software, vol. 26, no. 4, pp. 395-405, 2011.

[28] Y. Chen, J. Yu, and S. Khan, "The spatial framework for weight sensitivity analysis in AHP-based multi-criteria decision making," Environmental Modelling \& Software, vol. 48, pp. 129140, 2013.

[29] J. Krois and A. Schulte, "GIS-based multi-criteria evaluation to identify potential sites for soil and water conservation techniques in the Ronquillo watershed, northern Peru," Applied Geography, vol. 51, pp. 131-142, 2014.

[30] K. Lidouh, Y. De Smet, and E. Zimányi, "An adaptation of the GAIA visualization method for cartography," in Proceedings of the IEEE Symposium on Computational Intelligence in Multicriteria Decision-Making, 2011.

[31] S. Greco, B. Matarazzo, and R. Slowinski, "Rough sets methodology for sorting problems in presence of multiple attributes and criteria," European Journal of Operational Research, vol. 138, no. 2, pp. 247-259, 2002.

[32] R. Slowinski, S. Greco, and B. Matarazzo, "Rough set and rulebased multicriteria decision aiding," Pesquisa Operacional, vol. 32, no. 2, pp. 213-269, 2012.

[33] S. Chakhar, A. Ishizaka, A. Labib, and I. Saad, "Dominancebased rough set approach for group decisions," European Journal of Operational Research, vol. 251, no. 1, pp. 206-224, 2016.

[34] J. Blaszczynski, S. Greco, B. Matarazzo, R. Slowinski, and M. Szelag, "jMAF-dominance-based rough set data analysis framework," in Rough Sets and Intelligent Systems-Professor Zdzislaw Pawlak in Memoriam, pp. 185-209, Springer, 2013.

[35] J. L. Ratton, C. Galvão, M. Fernandez, and C. Galvão, "Pact for life and the reduction of homicides in the State of Pernambuco," Stability: International Journal of Security \& Development, vol. 3 , no. 1, pp. 1-15, 2014.
[36] S. D. Levitt, "Alternative strategies for identifying the link between unemployment and crime," Journal of Quantitative Criminology, vol. 17, no. 4, pp. 377-390, 2001.

[37] P. Fajnzylber, D. Lederman, and N. Loayza, "What causes violent crime?” European Economic Review, vol. 46, no. 7, pp. 1323-1357, 2002.

[38] F. Zifu, S. Hong, and W. Lihua, "Research of the classification model based on dominance rough set approach for china emergency communication," Mathematical Problems in Engineering, vol. 2015, Article ID 428218, 8 pages, 2015.

[39] D. V. E. S. Pereira and C. M. D. M. Mota, "Human development index based on ELECTRE TRI-C multicriteria method: an application in the city of Recife," Social Indicators Research, vol. 125, no. 1, pp. 19-45, 2016.

[40] C. Zopounidis and M. Doumpos, "Multicriteria classification and sorting methods: a literature review," European Journal of Operational Research, vol. 138, no. 2, pp. 229-246, 2002.

[41] S. Greco, B. Matarazzo, and R. Slowinski, "Dominance-based rough set approach to decision involving multiple decision makers," in Rough Sets and Current Trends in Computing, vol. 4259, pp. 306-317, Springer, Kobe, Japan, 2006.

[42] S. Chakhar and I. Saad, "Dominance-based rough set approach for groups in multicriteria classification problems," Decision Support Systems, vol. 54, no. 1, pp. 372-380, 2012. 


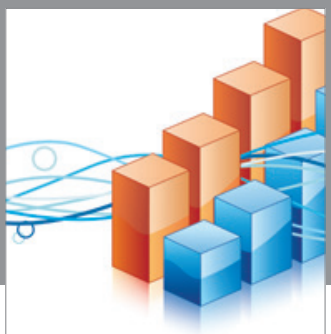

Advances in

Operations Research

vatem alat4

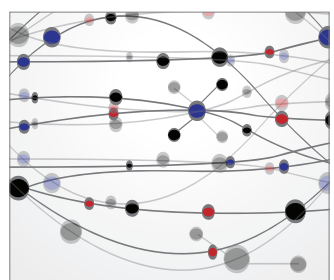

\section{The Scientific} World Journal
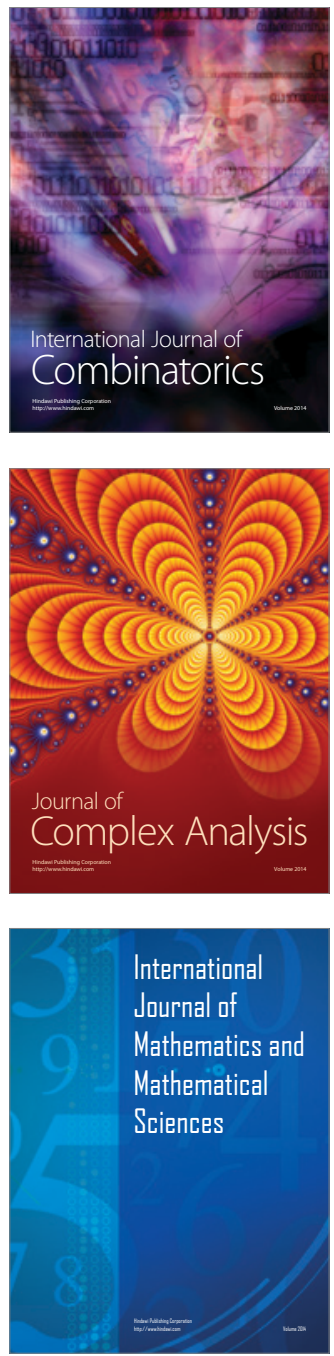
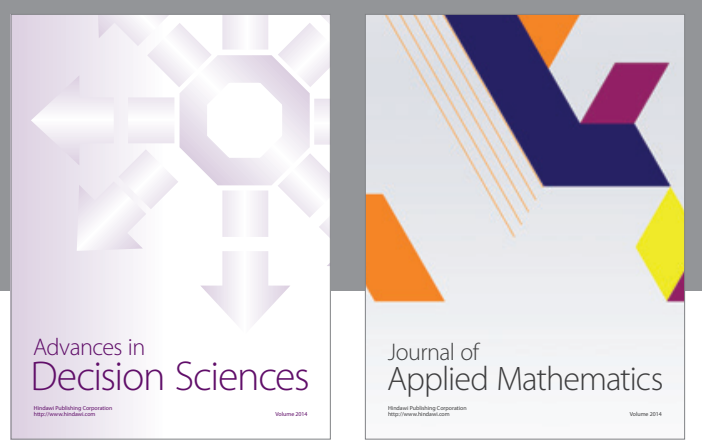

Algebra

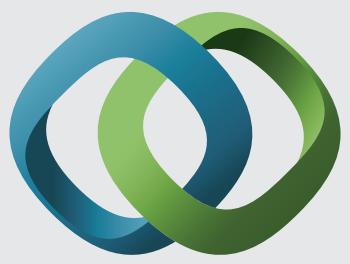

\section{Hindawi}

Submit your manuscripts at

http://www.hindawi.com
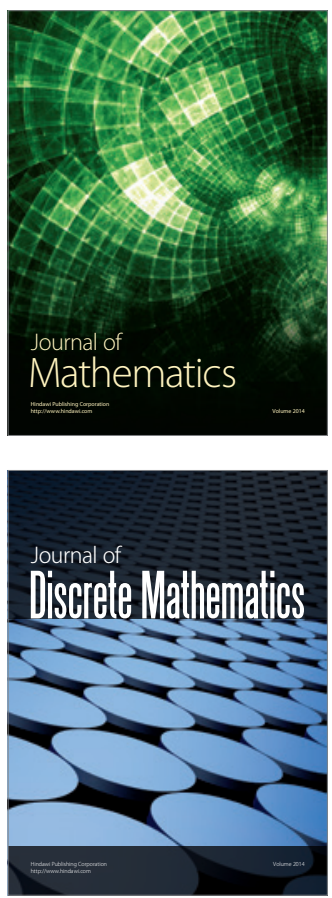

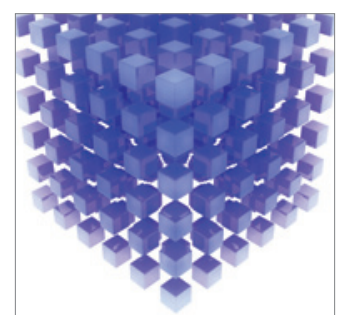

Mathematical Problems in Engineering
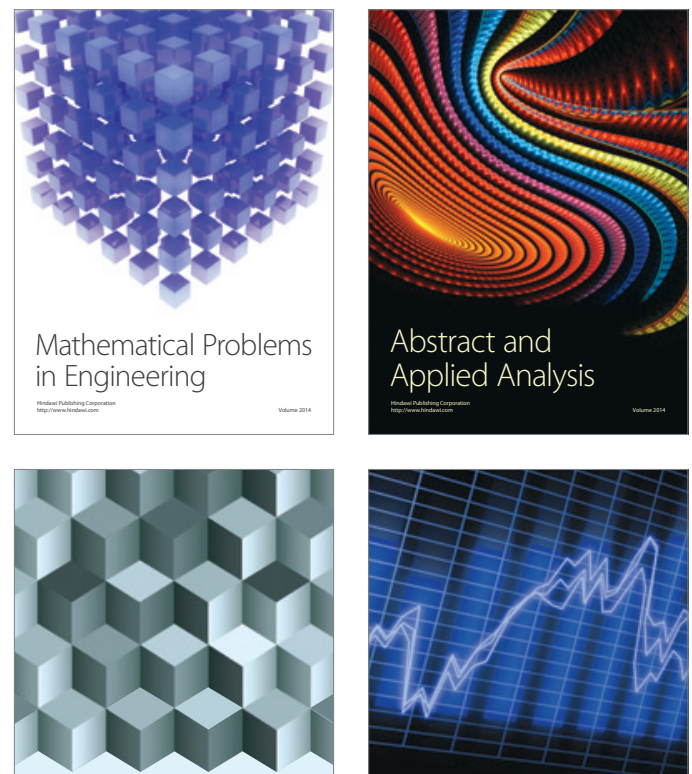

Journal of

Function Spaces

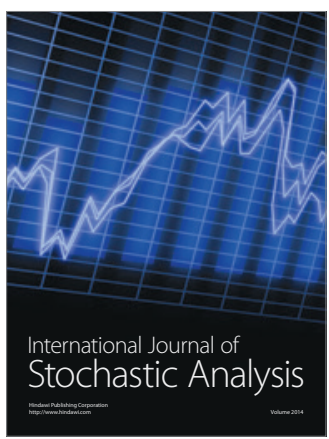

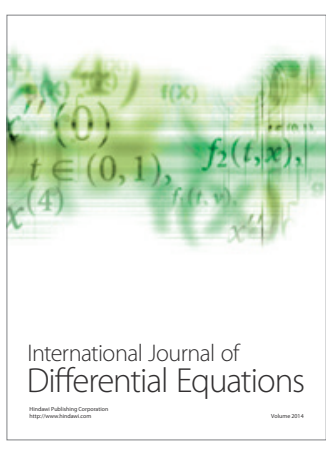
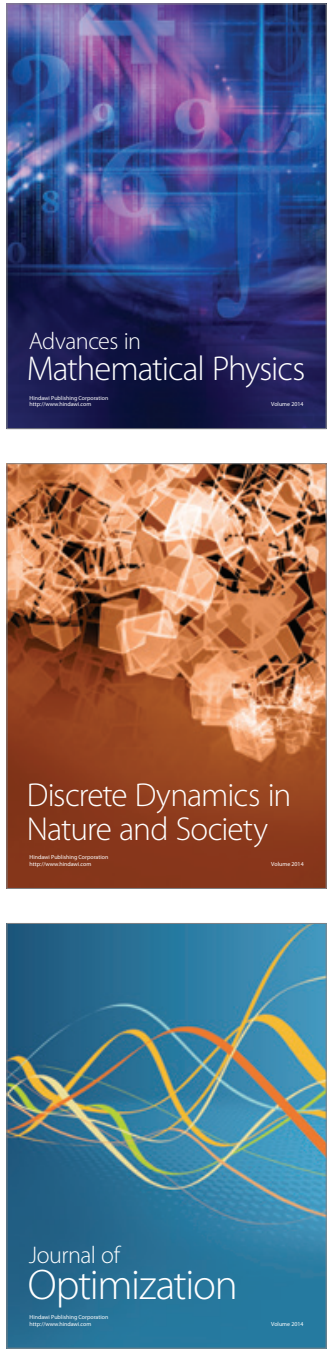